\title{
Child and adolescent psychiatry training in Nepal: early career psychiatrists' perspective
}

Utkarsh Karki ${ }^{*}$, Yugesh Rai ${ }^{2}$, Gunjan Dhonju³ , Eesha Sharma ${ }^{1}$, Preeti Jacob', John Vijay Sagar Kommu and Shekhar P. Seshadri ${ }^{1}$

\begin{abstract}
Background: Nepal is a developing low-income country in Southeast Asia. There is a huge burden of child and adolescent mental health (CAMH) in Nepal which has a population of around 29 million and $40-50 \%$ of the population comprises of children and adolescents. Child and Adolescent Psychiatry (CAP) has not been formally recognized as a subspecialty in Nepal and there is no standardized curriculum for CAP training. The objectives of the survey were to identify the current status of training, shortfalls and to explore the training experiences of early career psychiatrists (ECPs) in Nepal.
\end{abstract}

Methods: The participants were ECPs in Nepal. An online questionnaire was created consisting of 20 questions including 3 questions requiring an answer indicating a level of agreement scored on a ten-point scale. Questionnaire using google form was e-mailed with the uniform resource locator (URL). Respondents anonymously answered the questions. The survey was open from 01/01/2019 to 01/04/2019.

Results: Response rate was 83.69\%. Around $42 \%(n=32)$ were trainees in Doctor of Medicine (MD) Psychiatry and $58 \%(n=45)$ of respondents had completed their MD Psychiatry. More than half of the ECPs had not received formal training specific to CAP. Seventy percent $(n=54)$ ECPs reported that their current workplace did not have a specific unit to address psychological problems in children and adolescents. However, $62 \%(n=48)$ of ECPs came across 10 CAP cases per week. On a ten-point scale, mean score of ECPs confidence in diagnosing, management and overall confidence in CAP cases were $5.18 \pm 1.56,4.58 \pm 1.59$ and $4.67 \pm 1.62$ respectively. Fifty-four percent $(n=42)$ of respondents rated their training as limited and $74 \%(n=57)$ of them wanted additional training in CAP. Psychological intervention, psychotherapy and a fellowship course were the additional training most of the ECPs wanted to receive.

Conclusion: Despite significant exposure to CAP patients in daily practice, ECPs self-evaluated their training as inadequate and there is no standardized CAP training program in Nepal for ECPs. The desire of ECPs to receive additional training in CAP is highly encouraging and positive. We advocate for the development and incorporation of CAP training in current psychiatry training to fulfill these unmet training needs in Nepal.

Keywords: Child and adolescent psychiatry, Training, Early career psychiatrists, Nepal, Low income country

*Correspondence: karkiutkarsh@gmail.com

1 Department of Child and Adolescent Psychiatry, National Institute of Mental Health and Neuro Sciences, Bengaluru, India

Full list of author information is available at the end of the article

\section{Background}

Children and adolescents constitute almost a third ( $2 \cdot 2$ billion individuals) of the world's population and almost $90 \%$ live in low and middle-income countries (LAMIC), where they form up to $50 \%$ of the population. Mental health problems affect $10-20 \%$ of children and adolescents worldwide [1].

Half of the mental disorders are estimated to have onset by the age of 14 years [2]. Early identification and 
treatment of these disorders can improve the outcome and prognosis of psychiatric illnesses. However the major hindrances for mental health of children and adolescents in LAMIC are-lack of evidence on delivery of treatments, low levels of detection of child mental disorders, and shortage of skilled child mental health professionals [3]. Therefore, in these countries there is a vast gap between child and adolescent mental health (CAMH) needs (as measured through burden of disease estimates) and the availability of CAMH resources. The term "early career psychiatrists" include psychiatry trainees and psychiatrists within 7 years after specializing in psychiatry (i.e. finishing the whole time equivalent postgraduate specialty training in the respective country. [4].

Nepal is a low-income country in Southeast Asia. It has a population of around 29 million, and $40-50 \%$ of the population comprise of children and adolescents [5]. The Ministry of Health and Population of Nepal estimates that about $15-20 \%$ of this population (2-3 million) may suffer from some form of mental disorder [6, 7]. Many children in Nepal are living under multidimensional poverty as measured across health, education and living standards [8]. They are exposed to child labor, war, violence, sexual abuse, human trafficking and natural disasters like earthquakes, floods and landslides. Such factors are shown to have negative influences on child development ultimately leading to mental illnesses [9].

According to the World Health Organization Assessment Instrument for Mental Health Systems (WHO-AIMS) report on mental health in Nepal 2006, there were 18 outpatient mental health facilities available, 3-day treatment facilities, and 17 community based inpatient psychiatry facilities in addition to the mental hospital in Kathmandu, but there were no separate facilities for children and adolescents [10]. Only recently, has there been greater importance given to identifying and treating mental disorders in children $[6,7]$. The only child and adolescent psychiatry service in Nepal was set up at Kanti Children's Hospital, Kathmandu in collaboration with Non-Governmental Organizations (NGOs) in July 2015; there are as yet no inpatient facilities [11]. There is also an acute shortage of child and adolescent mental health professionals with only two child and adolescent psychiatrists in the whole country.

Currently, about 20 Medical Colleges are operating in Nepal with a minimum time period for completion of Bachelor of Medicine and Surgery (MBBS) course between 5 and $1 / 2$ years to 6 years. Post graduate training (residency) or MD courses are run in 14 out of 20 medical colleges. However, training for MD Psychiatry are provided in only 12 out of the 14 medical colleges. Child and Adolescent Psychiatry services and training provisions are very limited and confined to only few medical colleges. No specialized post graduate training in child and adolescent psychiatry is available in Nepal. Whether educators provide training of sufficient duration and depth for trainees to assess, diagnose and manage child and adolescent psychiatry patients remains unevaluated.

Taken together, despite the large number of child and adolescent mental illnesses and the importance for early treatment, there is no information available about child and adolescent psychiatry training in Nepal. The current study was designed to understand whether the current psychiatric training, duration of training and modality of training is adequate for trainees to assess, diagnose and manage children and adolescents with mental disorders. Understanding of the current status of CAP training across Nepal, short falls and training needs can serve to improve standards of training and sensitize the concerned authorities to develop and incorporate CAP training curriculum in the post graduate training in Nepal as well as other LAMIC.

\section{Methods \\ Participants}

The participants of this study were early career psychiatrists in Nepal. Early career psychiatrists (psychiatry trainees and psychiatrists within 7 years after specializing in psychiatry) were contacted through email and a questionnaire to be filled via google form was sent with the URL. The Psychiatric Association of Nepal (PAN) was contacted to collect the list of early career psychiatrists. Representatives or members of PAN from their respective home towns were contacted via e mail to obtain the contacts (email) of individuals who are currently undergoing training in Psychiatry. The study's objective was clearly stated on the online survey system's web page. The survey was conducted anonymously. A consent form was sent along with the URL link. Answering the questionnaire after reading the consent was considered to constitute consent to participate in the study. Ethics approval was sought from the Ethics Committee of National Institute of Mental Health and Neuro Sciences (NIMHANS), Bengaluru. The survey period was from 1st January to 1st April 2019.

\section{Questionnaire}

The questionnaire consisted of twenty questions which included: (1) description of the respondents (2) CAP training characteristics (3) CAP self -evaluation and (4) three open ended questions regarding their desire for additional CAP training.

The survey contained three types of responses: single and multiple-choice responses, open responses and responses on a ten -point Likert scale. 
Table 1 Description of the early career psychiatrists' $(n=77)$

\begin{tabular}{lr}
\hline Characteristics & $\mathbf{n}(\%)$ \\
\hline Current positions & $12(37.5)$ \\
Trainee in MD psychiatry & $10(31.3)$ \\
Year 1 & $10(31.3)$ \\
Year 2 & $32(41.6)$ \\
Year 3 & $11(24.4)$ \\
Total & $9(20.0)$ \\
Completed MD psychiatry & $14(31.1)$ \\
1 year & $6(13.3)$ \\
2 years & $5(11.1)$ \\
3 years & $45(58.4)$ \\
4 years & \\
5 years & \\
Total & \\
\hline
\end{tabular}

Table 2 Description of training characteristics

\begin{tabular}{lr}
\hline Characteristics & $\mathbf{n}(\%)$ \\
\hline Type of CAP training receiving or received & $7(9.3)$ \\
E-learning/online training & $38(50.7)$ \\
Clinical postings & $28(37.3)$ \\
Group discussions & $47(62.7)$ \\
Case presentations & $25(33.3)$ \\
Minimal or no formal training & $23(29.9)$ \\
Dedicated CAP unit or department in the place of training or work \\
Present & $54(70.1)$ \\
Absent & $3(3.9)$ \\
No of CAP patients seen per week & $48(62.3)$ \\
None & $19(24.7)$ \\
One to ten & $7(9.1)$ \\
Ten to twenty & \\
More than twenty & $5(6.5)$ \\
How often are childhood psychiatric disorders suspected & $51(66.2)$ \\
Always suspected & $21(27.3)$ \\
Often suspected & \\
Sometimes suspected &
\end{tabular}

\section{Statistical analysis}

Study results were expressed as frequency, percentages and mean \pm SD.

\section{Results}

Out of 92 ECPs we received 77 (83.69\%) responses. Tables 1, 2 and Fig. 1 summarizes the description of ECPs and their training characteristics. Table 3 summarizes CAP self-evaluation and perceived training needs.

Answers for the open-ended questions regarding their desire of additional CAP training, the majority have mentioned about wanting to learn psychological

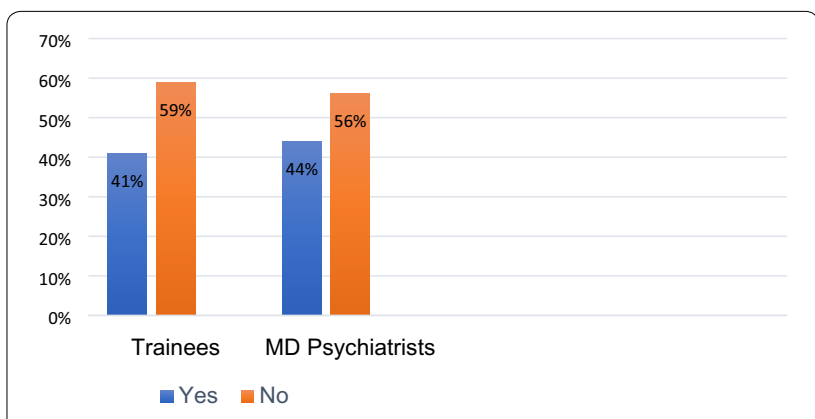

Fig. 1 Did ECP's receive training specific to CAP?

interventions, psychotherapy and a desire to undergo a short-term fellowship course in CAP. In addition, they have mentioned about the need to increase awareness, advocacy, conducting regular continued medical education (CME) on CAMH and incorporating CAP in their MD psychiatry training.

\section{Discussion}

This is the first study to explore the training experiences of ECPs of Nepal in Child and Adolescent Psychiatry. Our study reveals that about half of the ECPs have not received formal training specific to CAP. Although CAP has been incorporated in postgraduate training curriculum, there exists large variation in service organization, clinical exposure and supervision. CAP is not recognized as a subspecialty and currently lacks an international standardized training program [12] and the majority of trainees receive supervision from senior general psychiatrists. The post graduate training is often aligned with adult psychiatry and more weightage is given to general adult psychiatry in clinical examination. A specialized post graduate training in CAP is non-existent in 
Table 3 CAP self-evaluation and perceived training needs $(n=77)$

\begin{tabular}{|c|c|}
\hline Characteristics & n (\%) \\
\hline \multicolumn{2}{|l|}{ Overall rating in CAP training } \\
\hline Comprehensive & $1(1.3)$ \\
\hline Satisfactory & $22(28.6)$ \\
\hline Limited & $42(54.5)$ \\
\hline Grossly inadequate & $12(15.6)$ \\
\hline \multicolumn{2}{|l|}{ Readiness to take on a consultant role in CAP } \\
\hline Ready for the role & $5(6.5)$ \\
\hline Adequate but would benefit from further training & $38(49.4)$ \\
\hline Unprepared & $34(44.2)$ \\
\hline \multicolumn{2}{|l|}{ Want additional training in CAP } \\
\hline Yes & $57(74)$ \\
\hline No & $4(5.3)$ \\
\hline May be & $16(20.8)$ \\
\hline \multicolumn{2}{|c|}{$\begin{array}{l}\text { Mental health to be included in the curriculum for children and ado- } \\
\text { lescents }\end{array}$} \\
\hline Extremely important & $74(96.1)$ \\
\hline Slightly important & $3(3.9)$ \\
\hline Confidence in diagnosing CAP cases $^{\mathrm{a}}$ & $5.18 \pm 1.56$ \\
\hline Confidence in management/intervention of CAP cases $^{\mathrm{a}}$ & $4.58 \pm 1.59$ \\
\hline Overall confidence in CAPa & $4.67 \pm 1.62$ \\
\hline
\end{tabular}

a These results (score on a ten-point scale with 10 being the highest possible score) are expressed as the mean \pm SD

countries like Nepal and Vietnam [12]. In the Far East, there is an overall underdevelopment of CAP post graduate training systems with paucity of official guideline for CAP training [13]. On a positive note, India a neighboring country to Nepal has around 6 institutes for specialty training in child and adolescent psychiatry [14].

Seventy percent of ECPs reported that they did not have any specific unit or department to address psychological problems in children and adolescents. Most of CAP patients are reviewed in general psychiatric clinic and only few places have specific child guidance clinic. There are no specific inpatient facilities for child and adolescent and unfortunately children get admitted in adult psychiatric units. Furthermore, $62 \%$ of ECPs would come in clinical contact with 10 CAP cases per week during their training or clinical practice. Commonly seen disorders by ECPs during their training or current practice were neurodevelopmental disorders followed by dissociative disorders and anxiety disorders. It is reported that psychiatric trainees will often experience insufficient CAP cases in their general psychiatry training and senior psychiatrists might need to supervise trainees without enough CAP experience in their own training or practice [15]. There has not been an increase in CAP workforce despite an increase in the total number of psychiatrists in Nepal. With only two child psychiatrists in Nepal, there is an urgent need to train ECPs in CAP to meet the current service demands of mental health problem in children. It is encouraging to find a few post-graduate training centers have started to send trainees to Kanti Children Hospital, Nepal and NIMHANS, India for CAP exposure.

Several studies [16] have shown that exposure to certain subspecialties of psychiatry during initial phase of postgraduate training could have positive impact on career choice. In Nepal, the ratio of child and adolescent psychiatrists for 100,000 children aged 14 years or younger is 0.01 [12]. CAP can be made an attractive career choice by exposure to successfully treated cases, provision of educational seminars, case conferences, and a well-organized multidisciplinary team for CAP practice. Our study showed that half of the ECPs had clinical posting in CAP and engaged in case presentations. It is discouraging to find that one-third had no or minimal exposure to CAP in their residency training. We speculate that this figure might be higher than reported in this study as some ECPs were trained in Indian institutes that provide CAP exposure. In addition, two-third of ECPs rated their training in CAP as limited to grossly inadequate which needs to be addressed in the coming days but $22.6 \%$ of ECPs were satisfied with their training in CAP. It would have been prudent to explore the reasons for satisfaction, but we failed to capture this with the devised questionnaire. We speculate that those ECPs trained in few institutes with CAP training in Nepal and institutes in India may have constituted the $22.6 \%$ of ECPs satisfied with training. A study conducted in India with 451 respondents who had undergone post-graduate training in psychiatry perceived a rotation in CAP as a necessity and in the same study it was found that $26.2 \%$ of the group perceived the quality of their training in CAP to be "poor" or "very poor" [17]. This percentage is very less compared to our study wherein two-third of the ECPs perceived the training in CAP as limited or grossly inadequate. This could be due to the reason that post-graduate curricula for psychiatry in India stipulate mandatory postings in CAP for 2 or 3 months $[18,19]$.

Despite the average to below average self-rating in their confidence in diagnosing and management of CAP case $(5.18 \pm 1.56$ and $4.58 \pm 1.59)$ it is heartening and encouraging to know that two-third (74\%) of ECPs want additional training in CAP. A similar survey done in Japan demonstrated that early career psychiatrists' self-evaluated their clinical CAP experience as insufficient, and their CAP experience and CAP interest were found to correlate significantly [20]. Ninety-six percent $(n=74)$ also identify the importance of mental health in children and suggest it to be included in the curriculum of children and adolescents. However, obstacles to development of CAP postgraduate training may be stigma 
towards mental health issues and lack of funding which needs to be overcome.

With the above findings of the present study, we would like to emphasize the need of exposure of early career psychiatrists to more CAP cases to facilitate adequate and successful recruitment into CAP. In this regard, we recommend that all psychiatric training programs require (1) at least 2 months of intensive CAP training during residency under the supervision of a qualified child and adolescent psychiatrist, (2) short term training courses/ continued medical education/workshops on specific topics to enhance the psychiatric trainees' clinical skills to diagnose and treat child and adolescent cases.

\section{Limitations}

The answers to the survey were subjective assessments by ECPs and the respondent's training and clinical experience and diagnostic/treatment skills were not assessed objectively. Also, information was not obtained directly from the training program in each institution and the intention of each question could be interpreted slightly differently by respondents. Lastly, more qualitative exploration would have provided us with a greater understanding of CAP training and its shortfalls.

\section{Conclusion}

Our survey results show that despite significant exposure to CAP patients in daily practice, there is no standardized CAP training program in Nepal. Also, ECPs selfevaluated their training in CAP as insufficient. The desire of ECPs to receive additional training in CAP is highly encouraging and positive. In order to develop interest in CAP, more young psychiatrists need to be provided more exposure to CAP cases during the early stages of psychiatric training. We advocate for the development and incorporation of competency-based CAP training program in current post-graduate psychiatry training to fulfill these unmet training needs in Nepal.

\begin{abstract}
Abbreviations
CAP: Child and Adolescent Psychiatry; CAMH: Child and Adolescent Mental Health; ECP: Early Career Psychiatrists'; LAMIC: Low- and middle-income country; MD: Doctor of Medicine; NIMHANS: National Institute of Mental Health and Neuro Sciences; URL: Uniform Resource Locator.
\end{abstract}

\section{Acknowledgements}

The authors would like to thank all participants for completing the survey.

\section{Authors' contributions}

UK: Concepts, study design, intellectual content, Literature search, data acquisition, Statistical analysis, Manuscript preparation. YR: Concepts, study design, literature search, data analysis, manuscript preparation. GD: data acquisition, manuscript editing and review. ES: data analysis, statistical analysis, manuscript preparation, manuscript editing and review. PJ: intellectual content, manuscript editing and review. JVSK: intellectual content, manuscript editing and review. SPS: concept, intellectual content, manuscript editing and review. All authors read and approved the final manuscript.

\section{Funding}

Non- funded.

\section{Ethics approval and consent to participate}

Ethics approval was sought from the Ethics Committee of National Institute of Mental Health and Neuro Sciences (NIMHANS), Bengaluru. A consent form was sent along with the URL link. Answering the questionnaire after reading the consent was considered to constitute consent to participate in the study. All listed authors have approved the manuscript before submission and give consent for publication. All data generated or analyzed during this study are included in this published article.

\section{Competing interests}

The authors declare they have no competing interests.

\section{Author details}

${ }^{1}$ Department of Child and Adolescent Psychiatry, National Institute of Mental Health and Neuro Sciences, Bengaluru, India. ${ }^{2}$ Essex Partnership University NHS Trust, Colchester, UK. ${ }^{3}$ Child and Adolescent Psychiatry Unit, Kanti Children's Hospital, Kathmandu, Nepal.

Received: 4 October 2019 Accepted: 20 March 2020

Published online: 06 April 2020

\section{References}

1. UNICEF, PLAN, Save the Children T des hommes. One year after the Nepal earthquake. Statewide agricultural land use baseline. 2015. 1.

2. Kessler RC, Berglund P, Demler O, Jin RWE. Lifetime prevalence and ageof-onset distributions of DSM-IV disorders in the National Comorbidity Survey Replication. Arch Gen Psychiatry. 2005;62:593-602.

3. Patel V, Kieling C, Maulik PK, Divan G. Improving access to care for children with mental disorders: a global perspective. Arch Dis Child. 2013;98(5):323-7.

4. World Psychiatric Association. Terms of the reference of the WPA early career psychiatrists section. http://www.wpanet.org/early-career-psych iatrists. Accessed 8 September 2019.

5. Commission NP. Government of Nepal and OPHI, Nepal Multidimensional Poverty Index. Analysis towards Action Singha Durbar, Kathmandu. 2018. https://www.npc.gov.np/images/category/Nepal_MPI.pdf . Accessed Dec 2018.

6. Ministry of Health. Draft National Mental Health Policy. Nepal; 2017. https ://publichealthupdate.com/mental-health-policy-nepal/. Accessed Feb 2018.

7. Kunwar A.R, Tuladhar S. Establishment of National Center of Excellence in Child and Adolescent Psychiatry and Mental Health in Nepal; 2017 (unpublished report).

8. Unicef. Statistics and monitoring. 2008. http://www.unicef.org/ statistics.

9. Chaulagain A, Kunwar A, Watts S, Guerrero APS, Skokauskas N. Child and adolescent mental health problems in Nepal: a scoping review. Int J Ment Health Syst. 2019;13:53.

10. WHO-AIMS Report on Mental Health System in Nepal. Ministry of Health and Population Nepal. WHO Library Cataloguing-in-Publication data WHO-aims report on mental health system in Nepal. II Minist Heal Popul Nepal World Heal Organ. 2006. https://www.who.int/mental_health/ evidence/nepal_who_aims_report.pdf.

11. Kanti starts child and adolescen mental health OPD. The himalayan times. Kathmandu, Nepal; 2015. https://thehimalayantimes.com/kathmandu/ kanti-starts-child-and-adolescent-mental-health-opd/.

12. Sourander A, Chudal R, Skokauskas N, Al-Ansari AM, Klomek AB, Pornnoppadol C, Kolaitis G, Maezono J, Steinhausen HC, Slobodskaya H, Kankeo H, Regee J, Li L, Nguyen MH, Grimland M, Osokina O, Ong SH, Praharaj SK, Lesinskiene S, Fossum S, Wiguna T, Makasheva VA, Lehti V. Unmet needs of child and adolescent psychiatrists among Asian and European countries: does the Human Development Index (HDI) count? Eur Child Adolesc Psychiatry. 2018;27:5-8. 
13. Hirota T, Guerrero A, Sartorius N, Fung D, Leventhal B, Ong SH, Kaneko H, Kim B, Cho SC, Skokauskas N. Child and adolescent psychiatry in the far East. Psychiatry Clin Neurosci. 2015;69:171-7.

14. Kommu JVS, Jacob P. Specialty training in child and adolescent psychiatry in India. Eur Child Adolesc Psychiatry. 2020. https://doi.org/10.1007/s0078 7-019-01407-4.

15. Tateno M, Inagaki T, Saito T, Guerrero APS, Skokauskas N. Current challenges and future opportunities for child and adolescent psychiatry in Japan. Psychiatry Investig. 2017:14(5):525-31.

16. Tateno M, Kato T, Nakano W, Alan RT, Nakagawa A, Miyajima K, Kanba S, Nakamura J, Saito T. Attitudes of early-career psychiatrists in Japan toward child and adolescent psychiatry and their career decision. Psychiatry Clin Neurosci. 2010;64:199-201.

17. Grover S, Sahoo S, Srinivas B, Tripathi A, Avasthi A. Evaluation of psychiatry training in India: a survey of young psychiatrists under aegis of research, education, and training foundation of Indian Psychiatric Society. Indian J Psychiatry. 2018;60(4):445-60.
18. https://www.mciindia.org/CMS/information-desk/for-colleges/pg-curri cula2. (Accessed 10 Sept 2019).

19. https://nbe.edu.in/mainpdf/cirriculum/Psychiatry.pdf. (Accessed 10 Sept 2019).

20. Tateno M, Uchida N, Kikuchi S, Kawada R, Kobayashi S, Nakano W, Sasaki R, Shibata K, Shirasaka T, Suzuki M, Uehara K, Saito T, et al. The practice of child and adolescent psychiatry: a survey of early-career psychiatrists in Japan. Child Adolesc Psychiatry Mental Health. 2009;3:30.

\section{Publisher's Note}

Springer Nature remains neutral with regard to jurisdictional claims in published maps and institutional affiliations.
Ready to submit your research? Choose BMC and benefit from:

- fast, convenient online submission

- thorough peer review by experienced researchers in your field

- rapid publication on acceptance

- support for research data, including large and complex data types

- gold Open Access which fosters wider collaboration and increased citations

- maximum visibility for your research: over $100 \mathrm{M}$ website views per year

At BMC, research is always in progress.

Learn more biomedcentral.com/submissions 